\title{
An epibiont mediated increase in the susceptibility of Mytilus edulis to predation by Nucella lapillus
}

\author{
Jess Johansson* \\ *This study was conducted under the supervision of Professor Todd Gillis, \\ Department of Integrative Biology, \\ University of Guelph, Guelph, Ontario, Canada
}

\begin{abstract}
In marine organisms, the relationship that arises between two individuals where one organism biofouls the surface of a typically larger host organism is defined as epibiosis. Colonization of an organism by an epibiont can severely limit the feeding and reproductive abilities of the host and reduce overall fitness. Therefore, it is important to consider the benefits, if any, that the basibiont gains from this epibiotic relationship. In previous experiments, it was observed that barnacle epibionts protected Mytilus edulis from predation by Carcinus maenas, an intertidal predator. This study uses a choice experiment to deduce whether Semibalanus balanoides can mediate predation by another intertidal predator, the dogwhelk Nucella lapillus. N. lapillus preferred the substrate of barnacle-covered mussels to smooth-surface mussels, however specific preference to predate on these mussels was inconclusive from the results. The presence of $S$. balanoides on the shell surface of $M$. edulis decreased defensive behaviors, suggesting that the basibiont may be more vulnerable to predation because of this epibiotic relationship. If so, the relationship may border on parasitism if $M$. edulis fitness is significantly reduced.
\end{abstract}

$S^{u}$ ubject to extreme hydrodynamic forces, the body surfaces of intertidal organisms have evolved unique designs in response to the constant physical stresses in their environment. External modifications on the body surfaces of these organisms can alter the profile of the individual in the water column thereby increasing drag, which changes how environmental factors such as wave exposure influence the organism [1]. Such effects can have significant consequences on an animal's fitness and reproductive success.

Epibiosis describes the unique ecological interaction between two marine organisms whereby one individual - the epibiont - colonizes the body surface of a larger host organism known as the basibiont. By definition, the respective fitness of both the epibiont and basibiont are not impaired by this non-symbiotic relationship [2]. However, an epibiont modifies the host's morphology and subsequently alters the host's interactions with the ambient environment [3]. In an extreme and fluctuating environment such as the intertidal zone where physical constraints are more pronounced, the consequences of morphological alterations have the potential to be more severe for the basibiont.

Basibionts provide novel habitat and refuge to their associated organisms and in certain contexts are considered ecosystem engineers. Ecosystem engineers represent an ecological classification of taxa whose widespread distribution and abundance have a significant impact on the structure of their ambient community [4]. In the intertidal zone the highly competitive blue mussel Mytilus edulis reduces available resources such as space for competitors, although its hard shell surfaces provide substrate for colonization by epibionts such as the barnacle Semibalanus balanoides [5]. However, colonization of their outer shell surface by S. balanoides significantly alters the morphology of the individual by increasing its surface area, which in turn increases drag on the organism [4]. This poses a significant threat to the survival of $M$. edulis, whose life history is greatly influenced by hydrodynamic forces due to their sessile benthic adult stage.

As adults, $M$. edulis attach to its substrate through a specialized organ in their foot called the byssus that secretes mechanically strong protinaceous filaments. These filaments, called byssal threads, are produced at a rate dependant on the hydrodynamic properties of their environment and adhere to the surrounding substrate in both rocky and muddy shores [6]. As constraining environmental forces increase, individuals will require greater byssal thread production in order to remain attached to the substrate, which is met by a greater energy demand for the organism. Most often, $M$. edulis form large aggregates referred to as 'mussel beds,' which reduce the hydrodynamic forces acting upon a solitary individual. In these instances, secreted byssal threads attach to both the substrate as well as neighboring mussels to create a high density cluster of individuals. This also provides simultaneous defense against predation by drilling organisms, such as the dogwhelk Nucella lapillus by 
reducing the total exposed surface area of each individual [7]. Dislodgement of $M$. edulis from their substrate represents a significant threat to individual survival [8]. In this scenario, the organism may be washed into areas of low flow which reduces the resources available to the individual and decreases fitness.

With the barnacle epibiont $S$. balanoides, the compensation for loss of fitness by the basibiont is returned in the form of defense against predation by a top predator, the starfish, who display an inherent preference for the smooth shelled mussels of the sublittoral [9]. However, this benefit could be negated in the northern Atlantic Ocean where the common intertidal predatory dogwhelk $N$. lapillus readily consumes both $M$. edulis and the epibiont $S$. balanoides $[10,11]$. In defense to these attacks, species of mussels developed the capacity to use the byssal threads secreted from the byssus of their foot to trap and immobilize predatory dogwhelks $[12,13,14]$. Predation of thick-shelled organisms by $N$. lapillus is attributable to a modification to the ancestral radula, enabling the gastropod to drill through the hardened exterior of its chosen prey. Therefore, the addition of an epibiont to the outer shell of a prey organism does not necessarily hinder the feeding methods of $N$. lapillus compared to the methods engineered by other predators. Although the presence of an epibiont would provide a thicker surface through which the doghwelk would be required to drill, the epibiont is typically unable to colonize the entire shell surface and portions of the original surface remain exposed to predation.

Although $M$. edulis is preferred over $S$. balanoides as a food source by $N$. lapillus, the increased prey density could further attract the dogwhelk to prey upon these individuals [10]. Therefore, if the presence of the epibiont $S$. balanoides on the shell of $M$. edulis increases the mussel's susceptibility to predation by $N$. lapillus, then: (1) the distribution of $N$. lapillus will follow the distribution of barnacle-covered $M$. edulis, (2) barnacle-covered $M$. edulis individuals will experience greater predation rates by $N$. lapillus and (3) $N$. lapillus individuals foraging on barnacle-covered mussels will experience fewer defensive byssal thread attacks by $M$. edulis. As the presence of an epibiont increases drag on the basibiont, $M$. edulis would have to produce a greater number of byssal threads to attach to the substrate to prevent dislodgement. The actual production of byssal threads does not have the ability to increase due to the design of the byssus organ and only a finite number of byssal threads can be made. Barnacle-covered mussels will likely allocate more energy to producing byssal threads to further cement them to the substrate. This will reduce the risk of dislodgement.

\section{MATERIALS AND METHODS}

The outlined experimental methods were primarily derived from Casey and Chattopadhyay, 2008 [7].

\section{Specimen Collection Methods}

A total of $72 N$. lapillus individuals were collected from Green Point, St. Andrews, New Brunswick on August $11^{\text {th }}$ 2009. Individuals were starved for four days to increase the probability that they would feed during the experimental period. The shell heights of all specimens were measured and individuals from each stage structure were separated into nine groups with similar size distributions to limit the influence of predator size on prey choice.

All M. edulis groups were collected from Barr Road, St. Andrews, New Brunswick on August $15^{\text {th }}$ 2009. M. edulis groups were chosen based on number of individuals within the bed and the presence of $S$. balanoides on their outer shell. All groups contained five $M$. edulis individuals; nine groups were colonized by $S$. balanoides and nine groups possessed smooth surfaces. Unwanted organisms and debris such as chitons, gastropods and rocks were manually removed from the mussel groups prior to the start of the experiment using a scrub brush.

\section{Experimental Procedure}

Three sea tables with dimensions of 50 x 35 x $11 \mathrm{~cm}$ were divided into three equal chambers by mesh lining to create a total of nine experimental replicates of the uniform treatment. Attached to each sea table was a constant source of flow to ensure that the properties of the water such as temperature, $\mathrm{pH}$ and salinity remained constant throughout the experiment.

Within each replicate were two mussel groups placed on opposite sides of the partitioned area - one group which was colonized by $S$. balanoides and one group with smooth shell surfaces. Prior to the start of the experiment, eight $N$. lapillus individuals were placed in the middle of the partition area after which no more manipulations occurred to the experimental design.

Throughout the first two days of the experimental period, qualitative observations were made of the behaviour and displacement of $N$. lapillus. From these observations, an appropriate observation interval of two hours over the course of a 12 hour period was initiated for the final three days of the experiment. Each observational account recorded the distribution of $N$. lapillus with regards to substrate; whether the dogwhelks were located on the tank bottom, the mussel group with barnacles or the smooth mussel group. For the mussel group colonized by $S$. balanoides it was also noted whether the dogwhelk was located on the shell of the individual mussel or on the portion covered by barnacles.

At the end of the five-day experimental period, several measurements were made. For all replicates and within each group, the mortality of $M$. edulis and $S$. balanoides, the number of byssal threads attached to the substrate and the number of byssal threads attached to each dogwhelk were recorded for further analysis. Images of defensive byssal thread attacks by $M$. edulis on $N$. lapillus were recorded on a camera and pieced together to create a time lapse video of 


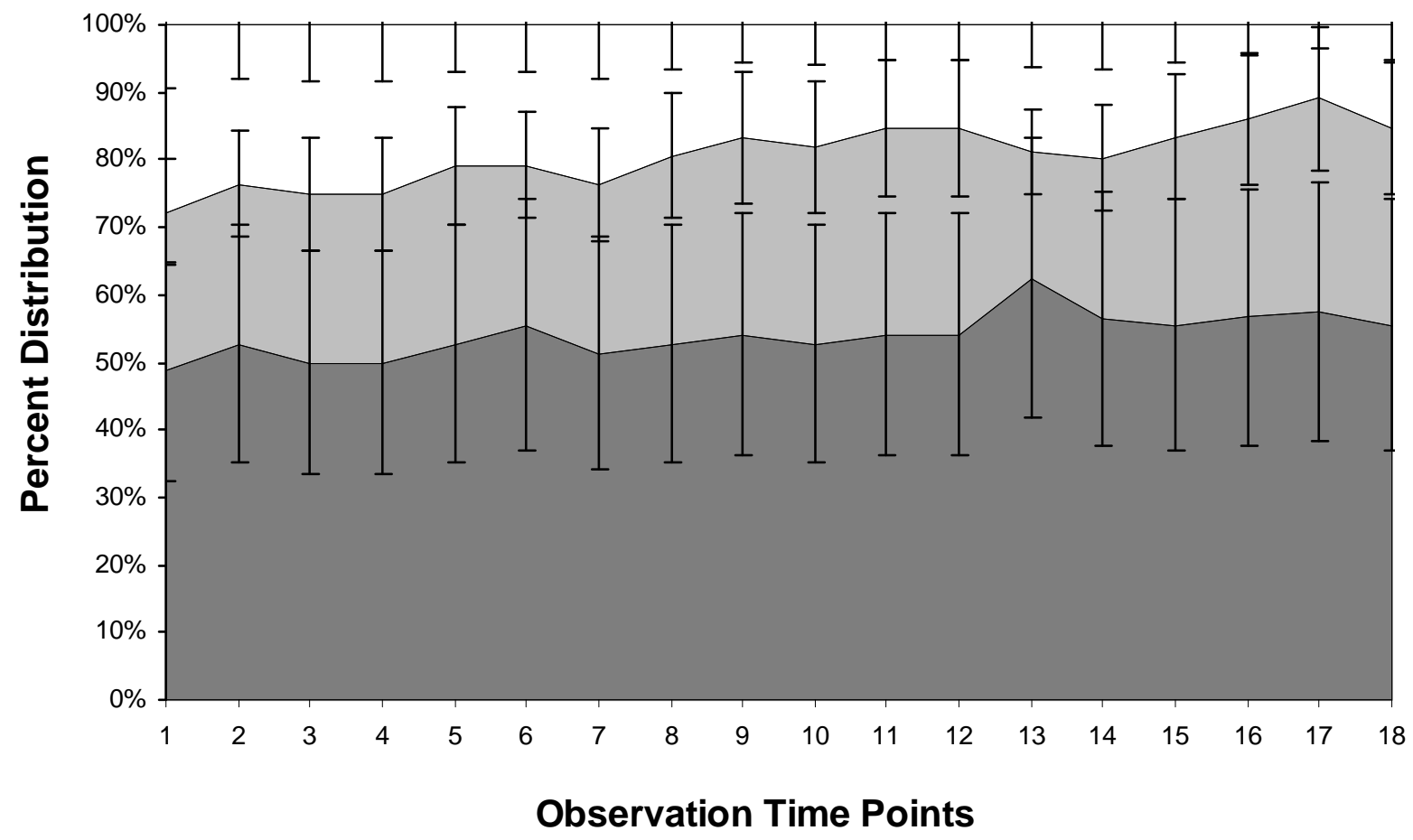

Barnacle-Covered Mussels

$\square$ Smooth-Surface Mussels

$\square$ Substrate

Figure 1: Greater Distribution of N. lapillus Across Barnacle-Covered Mussels.

The findings illustrated in the figure depict the distribution of $N$. Iapillus over the experimental period (n=72). Qualitative observations were made at two-hour intervals over the course of the final three days of the experiment. The percent distribution denotes the location of all $N$. lapillus individuals in the experiment with respect to substrate type: barnacle-covered mussel bed, smooth-surface mussel bed or substrate over time. The observed differences in the distribution of organisms on each substrate type were found to be statistically significant (ANOVA, $\mathbf{p}<\mathbf{0 . 0 0 0 1 )}$ ).

the event. The video material is available in the online supplementary material.

\section{RESULTS}

The distribution pattern of $N$. lapillus over the experimental period across the three substrate types - barnacle-covered mussels, smooth surface mussels and the aquarium substrate - was analyzed using ANOVA and found to be statistically significant $\left(\mathrm{F}_{2,24}=14.875, \mathrm{p}=6.28 \cdot 10^{-5}\right)$. This distribution pattern is depicted in Figure 1, whereby it should be noted that the surface of barnacle-covered mussels were significantly preferred to the other substrate types (Table 1).

The predation rate of $N$. lapillus on $M$. edulis was inferred from the number of drill holes present on the shell of each individual mussel. Comparisons between the number of holes drilled in the shells of barnacle-covered mussels versus smooth-surface mussels was not found to be significant (Student's t-test, $\mathrm{p}=0.1028$ )

The number of defensive byssal threads attached to $N$. lapillus individuals distributed on $M$. edulis was used to assess the defensive capabilities of the differing mussel types. Statistically significant correlations were found between the number of defensive byssal threads produced and the number of $N$. lapillus individuals situated on an individual mussel for both barnacle-covered and smoothsurface mussel types (Pearson's product moment correlation, $\mathrm{p}=0.002756$ and 0.001786 respectively). It was observed that smooth-surface mussels produced significantly more defensive byssal threads when predated by $N$. lapillus (Student's t-test, $\mathrm{p}=0.02572$ )(Figure 2). However, no significant differences were observed between the differing mussel types with respect to the number of byssal threads attached to the aquarium substrate (Student's t-test, $\mathrm{p}=-$ 0.232076).

\section{Discussion}

This lab study suggests that the presence of barnacle epibionts on the surface of mussels significantly alters the ecological distribution of their predator $N$. lapillus. However, no significant differences were observed with respect to the 


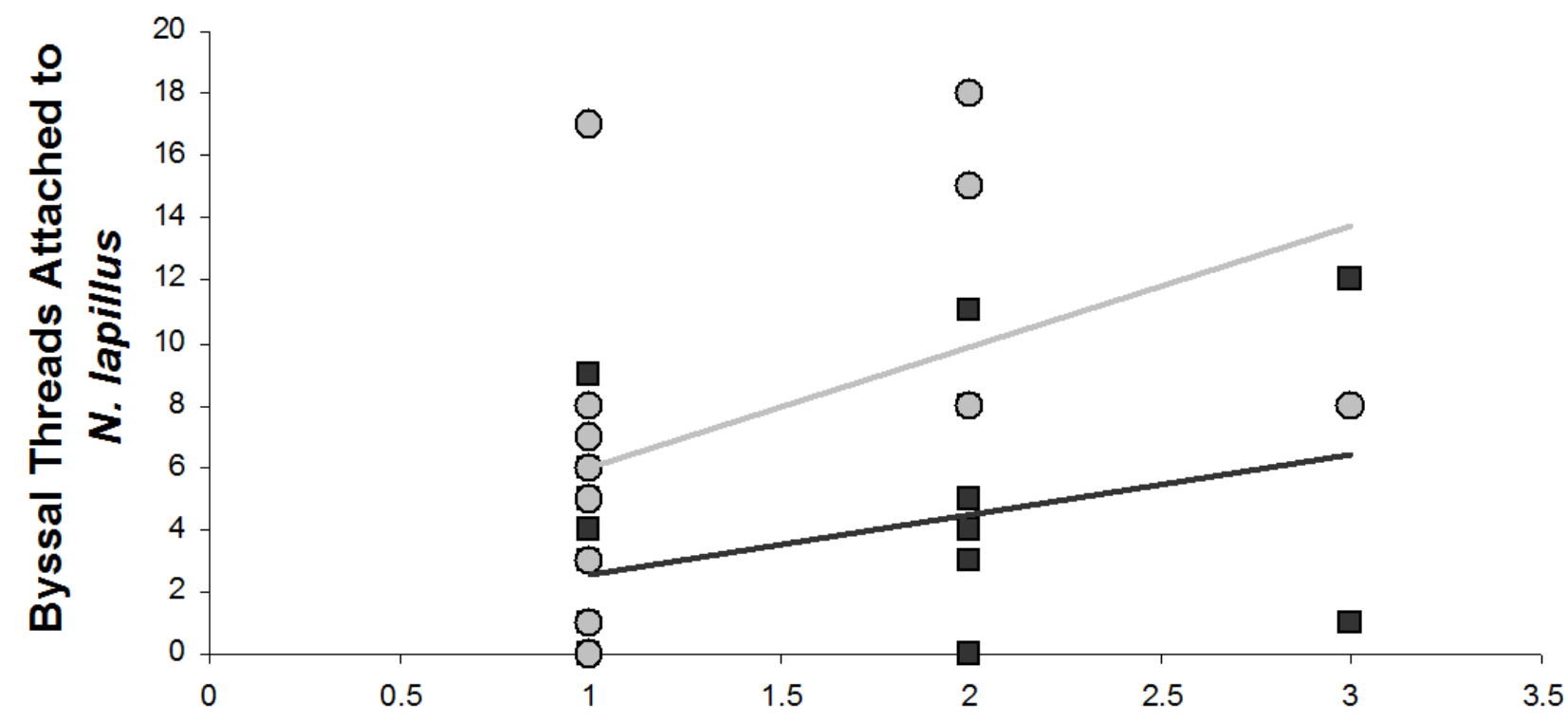

Number of $\mathbf{N}$. lapillus on $M$. edulis

\section{- Barnacle-Covered Mussels Linear (Barnacle-Covered Mussels)}

Figure 2: Barnacle covered mussels produce less byssal threads when attacked by $N$. lapillus.

Statistically significant correlations were observed between the number of defensive byssal threads produces and the number of $N$. lapillus individuals predating on a given mussel for both barnacle-covered mussels and smooth-surface mussels. Only data collected from $M$. edulis mussels that bossessed $N$. lavillus individuals on their shell surface was used (n=25 and 14 respectivelv). It

predation rate of $N$. lapillus on either mussel type. It was seen that barnacle-covered mussels inherently produced fewer defensive byssal threads than smooth-surface barnacles when under predation by $N$. lapillus [13]. For the purposes of scientific discourse all data will be discussed regardless of statistical significance and the inability of data to meet this criterion will be further explained by the sample size limitations of the proposed experimental design.

When selecting a habitat by choice, the bias of an individual will opt to occupy the space that increases its personal fitness along a gradient [15]. Previous choice experiments by Davenport et al. 1996 have demonstrated that $N$. lapillus prefers both the substrate of barnacle encrusted rock and bare rock to that of mussel carpets, attributing the choice to the availability of a low-risk food source [13]. However, in the Northern Atlantic intertidal zone the epibiotic relationship between $S$. balanoides and $M$. edulis is widespread and has important implications for basibiont predation risk as well as the distribution of $N$. lapillus. Of the available substrata, $N$. lapillus preferred the direct proximity of a food source provided by either smooth-surfaced or barnacle-covered mussels (Figure 1). However, the observed significant preference of barnacle-covered mussels by $N$. lapillus must provide a selective advantage to the predator. Consequently, this preference creates a disadvantage for the basibiont $M$. edulis who now experiences greater predation pressures as a product of increased $N$. lapillus density. Predation risk is a considerable stressor for $M$. edulis as the presence of both dogwhelk effluent and individuals significantly increases the heart rate of $M$. edulis individuals [16]. The positive relationship between predator density and basibiont stress will ultimately result in an increase in predation susceptibility for the basibiont. Similarly, this susceptibility can also be argued as a decrease in basibiont fitness due to the additional energy expenditure required to maintain the stressed state of the individual. The regulation of predation pressure against $M$. edulis by barnacle epibionts has been previously observed in the green crab Carcinus maenas, where epibiont colonization of mussel beds results in increased predation [1]. By adversely affecting the fitness of the basibiont in terms of biotic stress, the neutrally defined epibiotic relationship between $M$. edulis and $S$. balanoides should fall under questioning.

It is important to consider that gastropod densities and distributions do not always generate accurate measures of foraging activity and therefore may provide poor inferences of predation rates [17]. Despite the consistency of the observed distribution pattern, where the majority of $N$. lapillus was distributed on the barnacle-covered mussels, the predation rates against the two differing mussel types were 
Table 1: Statistical Analysis of Collected Data.

Statistical analysis of the collected data for each of the three experimental predictions is listed. The data sets compared, statistical test utilized and subsequent p-values are noted. Statistical significance was inferred at an alpha value of 0.05 .

\begin{tabular}{|c|c|c|c|c|}
\hline \multicolumn{5}{|c|}{ Statistical Analysis of Collected Data } \\
\hline \multicolumn{5}{|c|}{ Distribution of $N$. lapillus over Experimental Period (Day 3 to 5) } \\
\hline Comparison & Test & Test Statistic & Df & $P$ value \\
\hline $\begin{array}{l}\text { Barnacle-covered Mussels, } \\
\text { Smooth-surface Mussels, Substrate }\end{array}$ & ANOVA & 14.87510152 & 2,24 & $6.28 e^{-5}$ \\
\hline $\begin{array}{l}\text { Barnacle-covered Mussels, } \\
\text { Smooth-surfaced Mussels }\end{array}$ & $\begin{array}{l}\text { Student's T- } \\
\text { Test }\end{array}$ & // & 16 & $3.47 e^{-24}$ \\
\hline $\begin{array}{l}\text { Barnacle-covered Mussels, } \\
\text { Substrate }\end{array}$ & $\begin{array}{l}\text { Student's T- } \\
\text { Test }\end{array}$ & $/ /$ & 16 & $1.52 \mathrm{e}^{-25}$ \\
\hline Smooth-surface Mussels, Substrate & $\begin{array}{l}\text { Student's T- } \\
\text { Test }\end{array}$ & // & 16 & $2.62 \mathrm{e}^{-6}$ \\
\hline \multicolumn{5}{|c|}{ Predation by $N$. lapillus on $M$. edulis } \\
\hline Comparison & Test & Test Statistic & Df & $P$ value \\
\hline $\begin{array}{l}\text { Number of holes drilled in } \\
\text { Barnacle-covered Mussels, } \\
\text { Smooth-surface Mussels }\end{array}$ & $\begin{array}{l}\text { Student's T- } \\
\text { Test }\end{array}$ & // & 10 & 0.103 \\
\hline \multicolumn{5}{|c|}{ Byssal Threads Attached to N. lapillus } \\
\hline Comparison & Test & Slope (b) & $\begin{array}{l}\text { Correlation } \\
\text { Coefficient }\end{array}$ & $P$ value \\
\hline $\begin{array}{c}\text { Byssal threads attached to } N \text {. } \\
\text { lapillus on Barnacle-Covered } \\
\text { Mussels }\end{array}$ & $\begin{array}{l}\text { Linear } \\
\text { Regression }\end{array}$ & 2.05 & 3.375637 & 0.00276 \\
\hline $\begin{array}{c}\text { Byssal threads attached to } N \text {. } \\
\text { lapillus on Smooth-Surface } \\
\text { Mussels }\end{array}$ & $\begin{array}{l}\text { Linear } \\
\text { Regression }\end{array}$ & 3.876712 & 3.61117 & 0.00179 \\
\hline Comparison & Test & Test Statistic & Df & $P$ value \\
\hline $\begin{array}{c}\text { Defensive byssal threads produced } \\
\text { by Barnacle-covered Mussels, } \\
\text { Smooth-surface mussels }\end{array}$ & $\begin{array}{l}\text { Student's T- } \\
\text { Test }\end{array}$ & // & 17 & 0.0257 \\
\hline
\end{tabular}

not found to be statistically significant. As $N$. lapillus was observed actively feeding upon $S$. balanoides, it can be extrapolated that the higher density of dogwhelks on the mussel surface forced some individuals to consume the alternative prey. In field experiments, observations of $N$. lapillus have described a lower prey-handling time for $S$. balanoides than $M$. edulis [18]. This is attributable to both the smaller size of $S$. balanoides and the risk associated with its consumption. However, as $S$. balanoides sits erect on the outer surface of $M$. edulis shells, there is a considerable lack of refuge for the predator when foraging on its prey. Due to the smaller size of $S$. balanoides, it would be necessary to consume a greater number of individuals to gain the nutritional equivalent to one $M$. edulis. This increased foraging time is directly associated with an increase in predation risk by $N$. lapillus [18]. Although it may be more adaptive to prefer to consume barnacle-covered mussels, it is not feasible for all $N$. lapillus individuals distributed on these mussels to predate upon the basibiont simultaneously. There may be strong competitive forces amongst $N$. lapillus which 
forces less dominant individuals to predate upon $S$. balanoides as opposed to the desired M. edulis [9].

The addition of $S$. balanoides to the shell surface of $M$. edulis also severely alters the exterior morphology of the organism. As intertidal organisms, mussels have evolved a specific shape to withstand the hydrodynamic forces of their ambient environment; therefore changes to this morphology pose a significant risk to dislodgement. Since $M$. edulis remain attached to the substrate via byssal threads, it would be expected that the barnacle-covered mussels would utilize a higher proportion of their energy for producing byssal threads for better adhesion.. As such, it would be expected that these $M$. edulis individuals would have less available free energy to allocate to the production of defensive byssal threads to attack predators. However, only the latter proposed phenomenon was reflected in the results of this experiment (Figure 2). Although both mussel types produced a similar amount of byssal threads that adhered to the substrate of the aquarium, the barnacle-covered mussels produced significantly fewer defensive byssal threads. This is especially intriguing as these individuals experienced higher densities of $N$. lapillus on their surfaces, yet this increase in predation risk was met with fewer defensive behaviors. It is therefore possible that the presence of $S$. balanoides is causing stress to the basibiont, which results in weakened defensive abilities. This inability to cope with stress and subsequent poor allocation of resources could increase the susceptibility of $M$. edulis to predation by $N$. lapillus

It is important to note that although possible explanations and preliminary theories have been mentioned in this discussion, many of the comparisons on which they were based were not statistically significant. This is ultimately due to limitations of experimental design. Constraints of time and space only allowed a limited number of repetitions to run simultaneously. This resulted in a small number of experimental replicates, which in turn reduces the significance of the trends observed. The aquaria used for the replicates were small which provided a limit for sample size of each replicate. This resulted in a low number of individuals within each repetition, which in turn reduced the significance of the trends observed.

Within the experimental design, a serious effort was made to exclude confounding variables. The height of all $N$. lapillus individuals was measured and size-structured to create a normally distributed predator population within each replicate. All dogwhelks were collected from the same shoreline to avoid the effects of wave-exposure from impounding the results. This was especially important as wave-exposed $N$. lapillus have greater foraging rates than wave-sheltered individuals [18].

The distribution pattern of $N$. lapillus atop of barnacle-covered mussels supports the hypothesis that the addition of a barnacle epibiont increases the mussel's susceptibility to predation by dogwhelks. By attracting additional predatory individuals, the barnacle epibionts indirectly increase the stress experienced by their basibiont host - ultimately impairing their abilities to properly defend against attacks. However, despite this distribution pattern the predation rates on both barnacle-covered and smooth-surface mussels were not significantly different. The similar predation rates upon mussel individuals may have been affected by intraspecific competition among dogwhelks whereby weaker individuals are forced to consume the less desired prey, S. balanoides. An inclusive look at the overall predation rate (both barnacle and mussel prey types) should be analyzed in order to compare the environmental predation rate of both mussel types. If the overall predation rate of barnacle-covered mussels is greater than smooth-surface mussels, the original hypothesis may be supported. Future experiments should include fewer dogwhelk individuals per replicate in order to reduce intraspecific competition among the predators. The significant reduction in defensive byssal thread production by barnacle-covered mussels supports the hypothesis that $N$. lapillus increases the basibiont's susceptibility to predation. However, the mechanisms have not been inferred and are beyond the scope of this paper.

The addition of the barnacle epibiont, $S$. balanoides, to the surface of $M$. edulis increases the basibiont's susceptibility to predation by $N$. lapillus. From the collected data, it is impossible to detect which aspects of $M$. edulis' life cycle, survival and fitness would be most affected by this epibiotic relationship. This is an emerging area for future research.

\section{REFERENCES}

1. Wahl, M. (1989). Marine epibiosis. I: fouling and antifouling: some basic aspects. Mar Ecol Prog Ser. 58, 175-189.

2. Wahl, M. (2008). Ecological lever and interface ecology: epibiosis modulates the interactions between host and environment. Biofouling. 24 (6), 427-438.

3. Thieltges, D. W. and Buschbaum, C. (2006). Mechnisms of an epibiont burden: Crepidula fornicata increases byssus thread production by Mytilus edulis. J Mollusc Stud. 73, 75-77.

4. O’Connor, N. E., Crowe, T. P., McGrath, D. (2005). Effects of epibiotic algae on the survival, biomass and recruitment of mussels, Mytilus L. (Bivalvia: Mollusca). J Exp Marine Biol. 328, 265-276.

5. Durr, S. and Wahl, M. (2004). Isolated and combined impacts of blue mussels (Mytilus edulis) and barnacles (Balanus improvisus) on structure and diversity of a fouling community. J Exp Marine Biol. 306, 181-195.

6. Moeser, G. M. and Carrington, E. (2006). Seasonal variation in mussel byssal thread mechanics. J Exp Biol. 209, 1996-2003.

7. Casey, M. M. and Chattopadhyay, D. (2008). Clumping as a strategy against drilling predation: Implications for the fossil record. J Exp Marine Biol. 367, 174-179. 
8. O’Donnell, M. J. (2008). Reduction of wave forces within bare patches of mussel beds. Mar Ecol Prog Ser. 362, 157-167.

9. Saier, B. (2001). Direct and indirect effects of seastars Asterias rubens on mussel beds (Mytilus edulis) in the Wadden Sea. Sea Research. 46, 29-42.

10. Hughes, R. N. and Drewett, D. (1985). A comparison of the foraging behaviour of dogwhelks, Nucella lapillus (L.), feeding on barnacles or mussels on the shore. $J$ Mollusc Stud. 51, 73-77.

11. Freeman, A. S. and Hamer, C. E. (2009). The persistent effect of wave exposure on TMIIs and crab predation in Nucella lapillus. J Exp Marine Biol. 372, 58-63.

12. Petraitis, P. S. (1987). Immobilization of the predatory gastropod, Nucella lapillus by its prey, Mytilus edulis. Biol Bull. 172, 307-314.

13. Davenport, J., Moore, P.G. and LeComte, E. (1996). Observations on defensive interactions between predatory dogwhelks, Nucella lapillus (L.) and mussels, Mytilus edulis L. J Exp Marine Biol. 206, 133-147.

14. Farrell, E. D. and Crowe, T. P. (2007). The use of byssus threads by Mytilus edulis as an active defense against Nucella lapillus. J Mar Biol Assoc UK. 87, 559-564.

15. Edelaar, P., Siepeilski, A. M. and Clobert, J. (2008). Matching habitat choice causes directed gene flow: a neglected dimension in evolution and ecology. Evolution 62(10), 2462-2472.

16. Rovero, F., Hughes, R. N. and Chelazzi, G. (1999). Cardiac and behavioural responses of mussels to risk of pedation by dogwhelks. Anim Behav 57, 707-714.

17. Petraitis, P. S., Rhile, E. C. and Dudgeon, S. (2003). Survivorship of juvenile barnacles and mussels: spatial dependence and the origin of alternative communities. $J$ Exp Marine Biol 293, 217-236.

18. Rovero, F., Hughes, R. N. and Chelazzi, G. (1999a). The effect of experience on predatory behaviour of dogwhelks. Anim Behav. 57, 1241-1249. 